\title{
Lumican, an extracellular matrix proteoglycan, is a novel requisite for hepatic fibrosis
}

\author{
Anuradha Krishnan ${ }^{1}$, Xia Li ${ }^{1}$ Winston Whei-Yang Kao², Kimberly Viker ${ }^{1}$, Kim Butters ${ }^{1}$, Howard Masuoka ${ }^{1}$, \\ Bruce Knudsen ${ }^{1}$, Gregory Gores ${ }^{1}$ and Michael Charlton ${ }^{1}$
}

Lumican, an extracellular matrix proteoglycan was previously shown to be upregulated with increasing severity of nonalcoholic steatohepatitis (NASH). Although lumican is involved in collagen fibrillogenesis in extra-hepatic tissues, little is known about the role of lumican in hepatic disease. We therefore determined lumican expression in etiologies other than clinical NASH. Our results indicated that lumican is upregulated in clinical samples of hepatitis C virus infection, in experimental rodent models of chronic and acute liver injury and could additionally be induced in vitro in response to the pro-fibrotic cytokine transforming growth factor $\beta 1$ (TGF $\beta 1)$ and to lipotoxic palmitic acid. Together, these results suggested a role for lumican in hepatic fibrosis. To investigate the functional role of lumican in hepatic fibrosis, lumican null (Null) and wild-type (WT) littermates were administered carbon tetrachloride intra-peritoneally. Serum and liver tissue were analyzed for indices of liver injury, fibrosis, matrix turnover, and proliferation. Hepatic fibrosis was greatly reduced in null animals $(P<0.05)$. Paradoxically, gene expression of fibrosis-related genes such as TGF $\beta 1$ and collagen 1 was numerically higher in null animals though statistically insignificant from WT animals. On the other hand, $\alpha$ smooth muscle actin expression $(\alpha-S M A)$, a marker for activated fibroblasts, the main contributors of collagen production was significantly higher $(P<0.05)$ in null animals as compared with WT littermates. Among the matrix metalloproteases (MMP), MMP13 was significantly increased $(P<0.05)$ in null animals. Ultra-structural imaging indicated differences in the organization and spatial distribution of hepatic collagen fibrils of null and WT mice. Cell proliferation was significantly increased $(P<0.05)$ in null animals. We conclude that lumican is a prerequisite for hepatic fibrosis. The protective effect of lumican deficiency in hepatic fibrosis appears to be downstream of collagen production and mediated through the combined effects of impaired collagen fibrillogenesis, increased matrix turnover, and an enhanced proliferative response.

Laboratory Investigation (2012) 92, 1712-1725; doi:10.1038/labinvest.2012.121; published online 24 September 2012

KEYWORDS: carbon tetrachloride; collagen; extracellular matrix; hepatic fibrosis; lumican; proteoglycan; transforming growth factor $\beta 1$

Hepatic fibrosis, the common end point of many forms of chronic liver injury ${ }^{1}$ is characterized by increasing accumulation of collagen in the matrix resulting in 'scar' tissue. ${ }^{2} \mathrm{~A}$ cascade of molecular events follows the initial onset of cellular injury involving multiple cell types, signaling molecules, and interconnecting pathways that continue to be identified and delineated. Recently, we reported that lumican a $38-\mathrm{kDa}$ ECM proteoglycan, was significantly and progressively overexpressed in the hepatic proteome of patients with increasing severity of nonalcoholic steatohepatitis (NASH) and fibrosis, ${ }^{3}$ raising several fundamental questions pertaining to its expression in etiologies other than NASH and its regulation in response to known mediators of hepatic liver injury and fibrosis.
Lumican belongs to the small leucine-rich (SLRP) family of keratan sulfate proteoglycans. ${ }^{4,5}$ It has a well-established role in collagen fibril assembly in nonhepatic tissues, particularly the cornea, where fibril assembly is crucial to corneal transparency. ${ }^{6}$ Lumican knockout mice are characterized by an abnormal connective tissue phenotype, with fragile skin and cloudy cornea with thick or irregular collagen fibrils. ${ }^{7}$ Defects in connective tissue in mice deficient in SLRP's are associated with a wide array of other diseases resulting from abnormal collagen fibrillogenesis ranging from arthritis to muscular dystrophy. ${ }^{8}$ Recently, multiple other functions of lumican have been demonstrated: regulation of angiogenesis ${ }^{9}$ cell-cycle initiation, ${ }^{10}$ cell proliferation, ${ }^{11,12}$ cell migration, ${ }^{13}$ TLR4 signaling, ${ }^{14}$ and Fas-meditated immune activation. ${ }^{15,16}$

${ }^{1}$ Division of Gastroenterology and Hepatology, Mayo Clinic, Rochester, MN, USA and ${ }^{2}$ Department of Oncology, University of Cincinnati, Cincinnati, OH, USA Correspondence: Dr M Charlton, MD, Division of Gastroenterology and Hepatology, Mayo Clinic and Foundation CH-10, 200 First Street SW, Rochester, MN 55905 USA. E-mail: charlton.michael@mayo.edu

Received 31 October 2011; revised 29 June 2012; accepted 16 July 2012 
In the context of these known pleiotropic effects of lumican in other tissues, ${ }^{17}$ we speculated that lumican may play a diverse role in the pathophysiology of hepatic disease in humans. We sought evidence of hepatic lumican expression in etiologies representing three of the most common causes of acute and chronic hepatic injury: diet-induced steatohepatitis, drug toxicity, and viral infection. In all instances, lumican was upregulated. We also determined the in vitro regulation of lumican in response to pro-fibrotic transforming growth factor $\beta 1$ (TGF $\beta 1$ ) signaling in primary human hepatocytes. Given its well-established role in collagen fibrillogenesis in nonhepatic tissues, ${ }^{6}$ we hypothesized that lumican deficiency might protect against hepatic liver injury and fibrosis. We used the well-established rodent model of CCl4-induced hepatic fibrosis to determine if lumican-deficient mice were protected against liver injury and fibrosis.

\section{MATERIALS AND METHODS}

\section{Experimental Animals}

All animal experiments were conducted with the approval of the Institutional Animal Care and Use Committee of the Mayo Clinic. C57Bl/6 mice were assigned to two experimental feeding groups as described earlier. ${ }^{18}$ Briefly, animals were fed either a 'Fast food' (FF) diet (20\% saturated fat, 2000 p.p.m. cholesterol, 76A, TestDiet) or 'Standard chow' (SC) (5\% fat, 120 p.p.m. cholesterol, Diet Pico Lab). Additionally, both groups were provided with fructose (23.1 g/l, F2543; Sigma Aldrich, USA) and glucose (18.9 g/l,
49 158; Sigma Aldrich, USA) in their drinking water. Animals were reared for 6 months and sacrificed by carbon dioxide $\left(\mathrm{CO}_{2}\right)$ inhalation. Liver was excised and preserved in $10 \%$ buffered formalin or flash frozen and stored at $-80{ }^{\circ} \mathrm{C}$ for recovery of RNA.

In separate experiments, breeding pairs of lumican heterozygous mice received from Winston W-Y Kao, University of Cincinnati, $\mathrm{OH}$, were used to establish a colony. Six- to eight-week-old null and WT littermates were injected intraperitoneally with either carbon tetrachloride (CCl4) diluted $1: 5$ with corn oil $(n=6)$ or vehicle (corn oil only) at $1 \mathrm{ml} / \mathrm{kg}$ in an acute liver injury model (single injection only) or for a period of 1 month, twice weekly, in a chronic liver injury model. Animals were euthanized on the second day after the last CCl4 injection as described above. Serum AST was analyzed using automated procedures of the Mayo Clinic, Rochester, MN, USA.

\section{In Vitro Assays with Primary Human Hepatocytes and HuH7 Cell Line}

All experiments on human tissue samples were reviewed and approved by the Institutional Review Board of the Mayo Clinic. Primary human hepatocytes were isolated from surgically derived tissue. ${ }^{19}$ Isolated hepatocytes were plated in $100 \mathrm{~mm}$ collagen-coated Petri dishes or six-well collagencoated culture plates at 3 million hepatocytes/plate. Hepatocytes were allowed to settle overnight; culture medium was changed and TGF $\beta 1$ added to medium. Cells

Table 1 List of primers

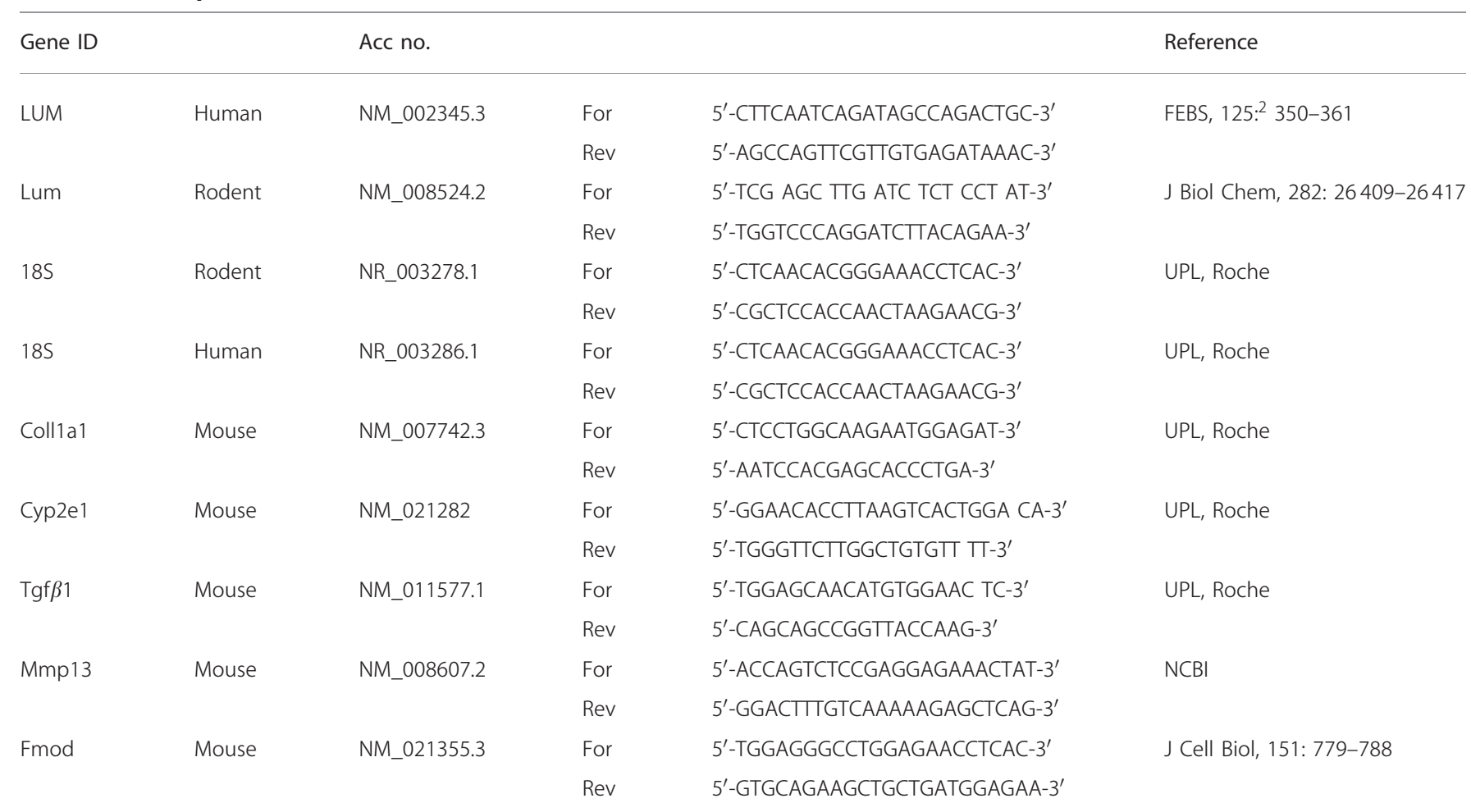


were treated with TGF $\beta 1$ ( 2 ng/ml; R\&D Systems, MN, USA) or with diluent. At specified time intervals, cells were harvested, washed in cold phosphate-buffered saline (PBS) and snap frozen for RNA extraction. The hepatocyte cell line Huh7 was seeded at 0.2 million/well in a six-well plate for $24 \mathrm{~h}$. Palmitic or stearic acid was added to the culture media at a concentration of $400 \mu \mathrm{M}$ and cultured for $6 \mathrm{~h}$ before recovery as described earlier. ${ }^{20}$

\section{Histology, Immunohistochemistry, and Digital Image Analysis}

All histology and immunostaining of tissue sections were carried out by the core facility of the Mayo Clinic, Rochester, MN, USA. Briefly, de-paraffinized, hydrated serial sections of liver were stained with hematoxylin and eosin, Masson's trichrome, and picrosirius red using standardized protocols. Additional serial sections were stained with antibodies against lumican (AF2846, R\&D Systems); $\alpha$ smooth muscle actin ( $\alpha$-SMA) (NB110-55432, Novus Biologicals); and Ki67 (TEC-Clone3, Dako). Staining for all antibodies was optimized to ensure specificity with no background staining. Bound antibodies were detected using diaminobenzidine tetrahydrochloride and sections were counter stained with hematoxylin. Quantitative analysis of stained sections was performed as previously described. ${ }^{3}$

\section{Protein Isolation and Western Blotting}

Total protein from frozen tissue samples was extracted in lysis buffer $(30 \mathrm{mM}$ Tris- $\mathrm{HCl} 150 \mathrm{mM} \mathrm{NaCl}, 10 \%$ glycerol,
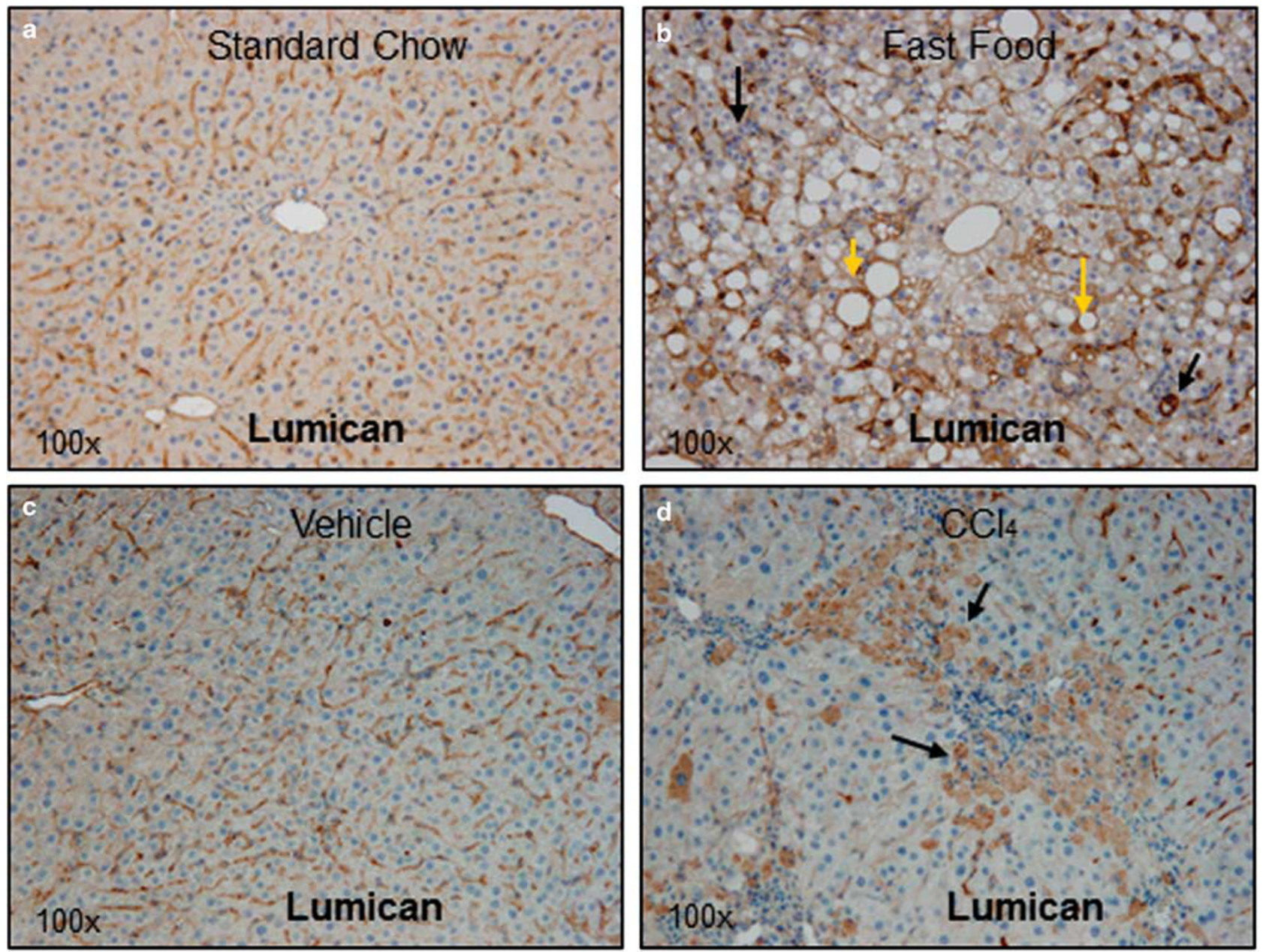

Figure 1 Lumican is upregulated in a rodent model of diet-induced steatohepatitis and in acute hepato-toxin induced liver injury. C57BI/6 mice were fed for 6 months either standard rodent chow or 'FF' (a combination of high fat, cholesterol and sugars). Liver sections were stained for lumican, an ECM proteoglycan. (a) In mice reared on SC, lumican is seen primarily localized to the hepatic sinusoids. (b) In mice reared on FF, cytoplasmic staining of hepatocytes is intense around areas of fat vacuoles (yellow arrows) and around inflammation (black arrows). In a second experiment, J129/B6 mice were administered intra-peritoneal injections of either vehicle (corn oil) or $\mathrm{CCl}_{4} @ 1 \mathrm{ml} / \mathrm{kg}$. (c) Lumican is seen primarily localized to the hepatic sinusoids in mice administered vehicle alone whereas (d) in animals administered CCl4, vacuolated hepatocytes clustered around areas of injury (black arrows) stain intensely for lumican. Magnification (a-d): $\times 100$. (e-h) Upon injury or stress, hepatocytes contribute to lumican production. (e-h) Serial sections of liver of mice reared on FF or treated with $\mathrm{CCl}_{4} @ 1 \mathrm{ml} / \mathrm{kg}$ were stained for lumican and ASMA to compare their in situ localization. (e) Hepatocytes containing lipid vacuoles or (g) injured, vacuolated hepatocytes stain densely for lumican; (f, h) ASMA is restricted to the sinusoids alone. Magnification: $\times 630$. 

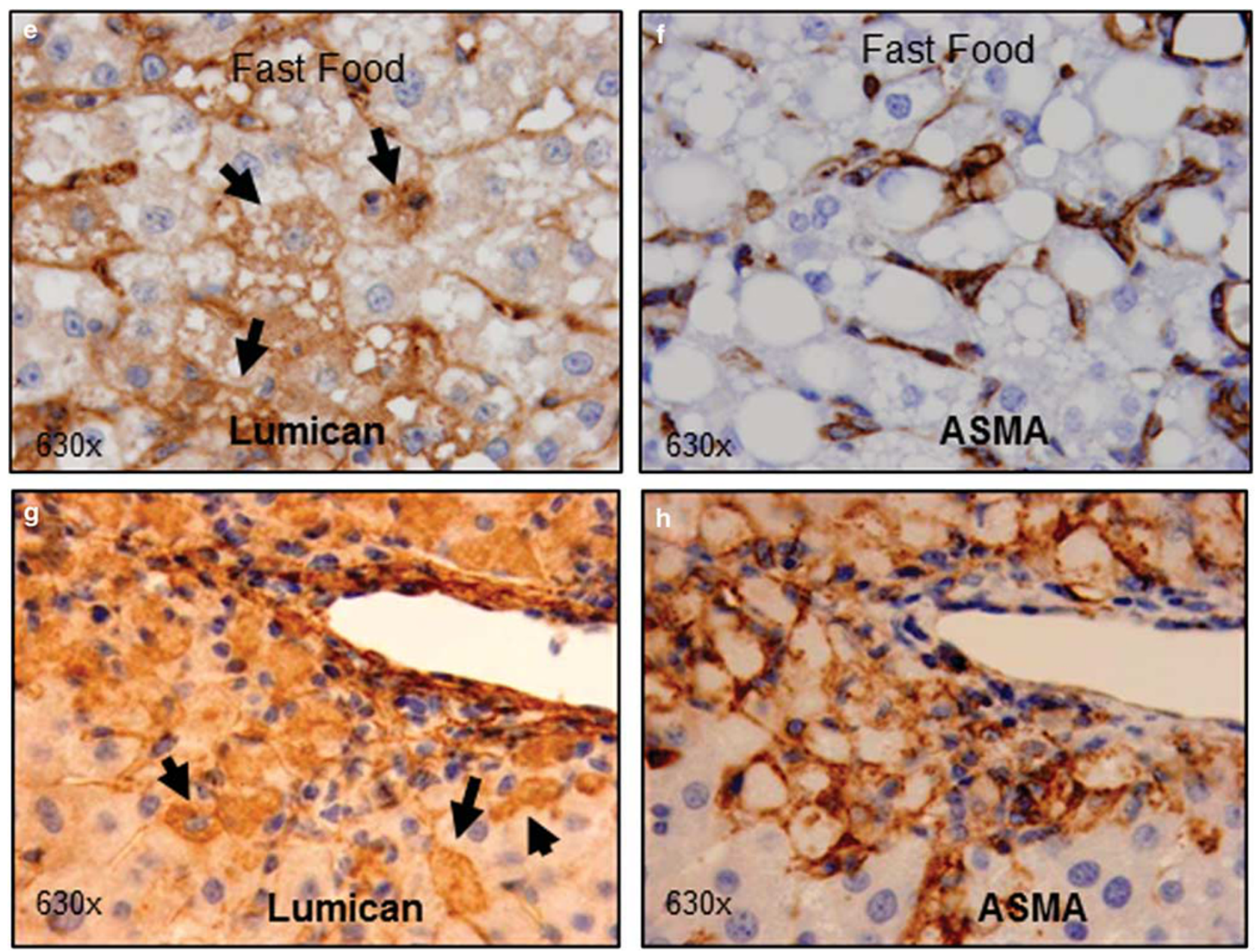

Figure 1 (Continued)

2\% Triton X-100, $1 \mathrm{mM}$ phenylmethylsulfonyl fluoride, protease inhibitor cocktail (539134, Calbiochem, USA). Equal quantities of protein $(20 \mu \mathrm{g})$ were resolved by electrophoresis in 10\% PAGE gel and transferred to PVDF membrane. Blots were probed with primary antibodies (lumican, AF2745, R\&D Systems; $\alpha$-tubulin ab18251, Abcam, USA) with appropriate secondary antibodies (474-1516, KPL; HAF017, R\&D Systems). Protein bands were visualized using an enhanced chemiluminescent substrate (Pierce, USA).

\section{RNA Isolation and Quantitative RT-PCR}

Total RNA was isolated from frozen liver tissue or cell pellets using the RNeasy Plus kit (Qiagen, GmbH, Germany). Equal quantities of total RNA was reverse transcribed into cDNA (05081866001, Roche, USA). Real-time PCR was performed on an iCycler (Bio-Rad, USA) in a volume of $20 \mu \mathrm{l}$ using Lightcycler 480 SYBR green1 Master (12239264001, Roche, USA). Primers are listed in Table 1. RNA expression was normalized to the combined average expression of two housekeeping genes, $18 \mathrm{~S}$ and GAPDH. Data are presented as relative expression.

\section{Ultra-Structural Imaging}

Healthy, age-matched lumican null or WT animals were anesthetized with ketamine $(100 \mathrm{mg} / \mathrm{kg})$ and xylazine $(10 \mathrm{mg} /$ $\mathrm{kg}$ ). The liver was perfused with heparinised saline followed by $2 \%$ glutaraldehyde in phosphate buffer ( $\mathrm{pH} 7.4)$. Excised liver was preserved in Trump's buffer before secondary fixation in $1 \%$ osmium tetraoxide and embedded in epoxy resin. Ultrathin sections were stained with uranyl acetate and lead citrate and visualized in a transmission electron microscope (Philip Cm10 TEM) of the Electron Microscope Core Facility, Rochester, MN, USA.

\section{Collagen Fibrillogenesis Assay}

Collagen fibril formation was measured as previously described $^{21}$ with the following modifications. Turbidity was measured at $340 \mathrm{~nm}$ in a UV sensitive 96-well plate (353261, BD Falcon microplates) using a total volume of $100 \mu \mathrm{l}$ at $30^{\circ} \mathrm{C}$ in a plate reader (DTX 800, Beckman Coulter, USA). Each assay consisted of $50 \mu \mathrm{l}$ of acid extracted type 1 rat tail collagen (BD Bioscience, USA) at $1 \mathrm{mg} / \mathrm{ml}(\mathrm{pH}$ corrected to 7.2 ) and $50 \mu \mathrm{l}$ of recombinant rhlumican (2847-Lu; R\&D Systems) 
a

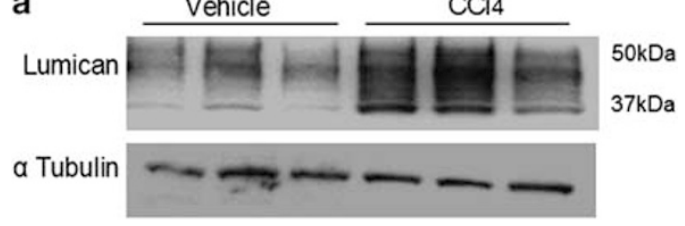

b

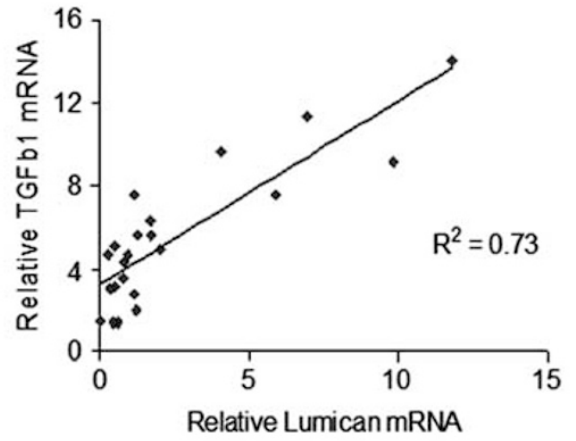

C

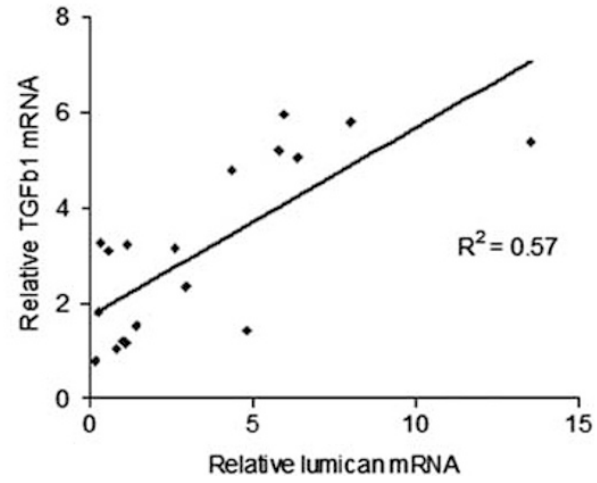

Figure 2 Lumican protein is increased in mice treated with $\mathrm{CCl} 4$ and correlates with TGF $\beta 1$ expression. (a) Western blot analysis of liver lysates of mice treated with $\mathrm{CCl} 4$ demonstrate increased expression of lumican as compared with control animals. Glycosylation of lumican protein is indicated by the extensive band that stretches from 37 to $50 \mathrm{kDa}$. (b, c) Lumican gene expression correlates positively with TGF $\beta 1$. Relative gene expression of lumican is plotted against relative gene expression of TGF $\beta 1$ (b) in all animals that were fed SC, and FF and (c) in all animals that were administered $\mathrm{CCl} 4$ or vehicle alone.

using $1 \times$ PBS as diluent. All solutions were maintained at $4{ }^{\circ} \mathrm{C}$. Collagen was added to the proteoglycan, mixed by pipetting and reading initiated immediately. Turbidity was measured every $2 \mathrm{~min}$ for $60 \mathrm{~min}$. Readings were blanked against the diluent buffer. Data were compared with collagen without rhlumican. Background readings of rhlumican at all doses and for all time points were monitored.

\section{Statistical Analysis}

Data are presented as mean \pm s.d. representing replications within an experiment. For all mouse experiments, the Kruskall-Wallis test was used to arrive at a global $P$-value. A $P$-value $<0.05$ was considered significant. Those parameters that tested below 0.05 were further analyzed by the Wilcoxon-ranked sum test for significance using two-sample normal approximation.
Table 2 Lumican gene expression in primary human hepatocytes in response to TGF $\beta 1$ signaling

\begin{tabular}{lccc}
\hline Time $(\mathrm{h})$ & TGF $\beta 1+$ & TGF $\beta 1-$ & $P$-value \\
\hline $\mathrm{Oh}$ & $1.00 \pm 0.10$ & $1.00 \pm 0.10$ & - \\
$24 \mathrm{~h}$ & $1.93 \pm 0.23$ & $0.88 \pm 0.28$ & 0.02 \\
$48 \mathrm{~h}$ & $2.75 \pm 0.64$ & $0.42 \pm 0.13$ & 0.01 \\
$72 \mathrm{~h}$ & $6.16 \pm 1.56$ & $0.85 \pm 0.20$ & 0.02 \\
\hline
\end{tabular}

\section{RESULTS}

Lumican Expression is Upregulated in Multiple Disease Etiologies

Lumican gene expression was examined in response to liver injury in two rodent models: diet-induced steatohepatitis and hepato-toxin (CCl4) induced acute necro-inflammation; and additionally in clinical samples of Hepatitis C Virus (HCV) infection. In the first instance, prolonged feeding with FF diet was shown to induce steatohepatitis with fibrosis. ${ }^{18}$ Immunostaining for lumican indicated that in animals fed SC, lumican was localized primarily to hepatic sinusoids (Figure 1a). By contrast, in animals reared on FF, lumican staining showed a mosaic pattern similar to that seen in NASH patients, ${ }^{3}$ where additional dense staining is visible in almost all hepatocytes, particularly around fat vacuoles and areas of inflammation (Figure 1b). Similarly, lumican was localized to sinusoids in mice administered vehicle (Figure 1c) whereas in animals administered CCl4, hepatocytes clustered around areas of necro-inflammation were intensely stained (Figure 1d). The differential localization of lumican in response to injury suggested that there may be multiple cellular sources for lumican within the liver. We compared immunostaining patterns for ASMA (a marker of activated pro-fibrotic cells) and for lumican in serial sections of individual animals to distinguish relative in vivo and in situ contribution of lumican by hepatocytes and stellate cells/myofibroblasts. In both FF- and CCl4treated animals, individual intact hepatocytes and/or clusters of necrotic hepatocytes stain intensely for lumican (Figures 1e and g). ASMA staining, on the other hand, is localized only to the hepatic sinusoids (Figures $1 \mathrm{f}$ and $\mathrm{h}$ ) with no staining in necrotic hepatocytes, suggesting that during inflammation and injury, hepatocytes may also contribute to hepatic lumican production. Further, we compared lumican gene expression in three cell lines representing different hepatic cell types: HuH7 (hepatocyte), LX2 (stellate), and H69 (cholangiocyte). Lumican gene expression normalized to total RNA in the hepatocyte cell line $\mathrm{HuH} 7$ was comparable to that of normal human liver with lower expression in the cholangiocyte and stellate cell line (Supplementary Figure 1).

Digital image analysis confirmed that lumican protein was twofold increased in FF-fed $(P<0.01)$ and fivefold increased in CCl4-treated $(P<0.005)$ animals. Gene expression analysis 

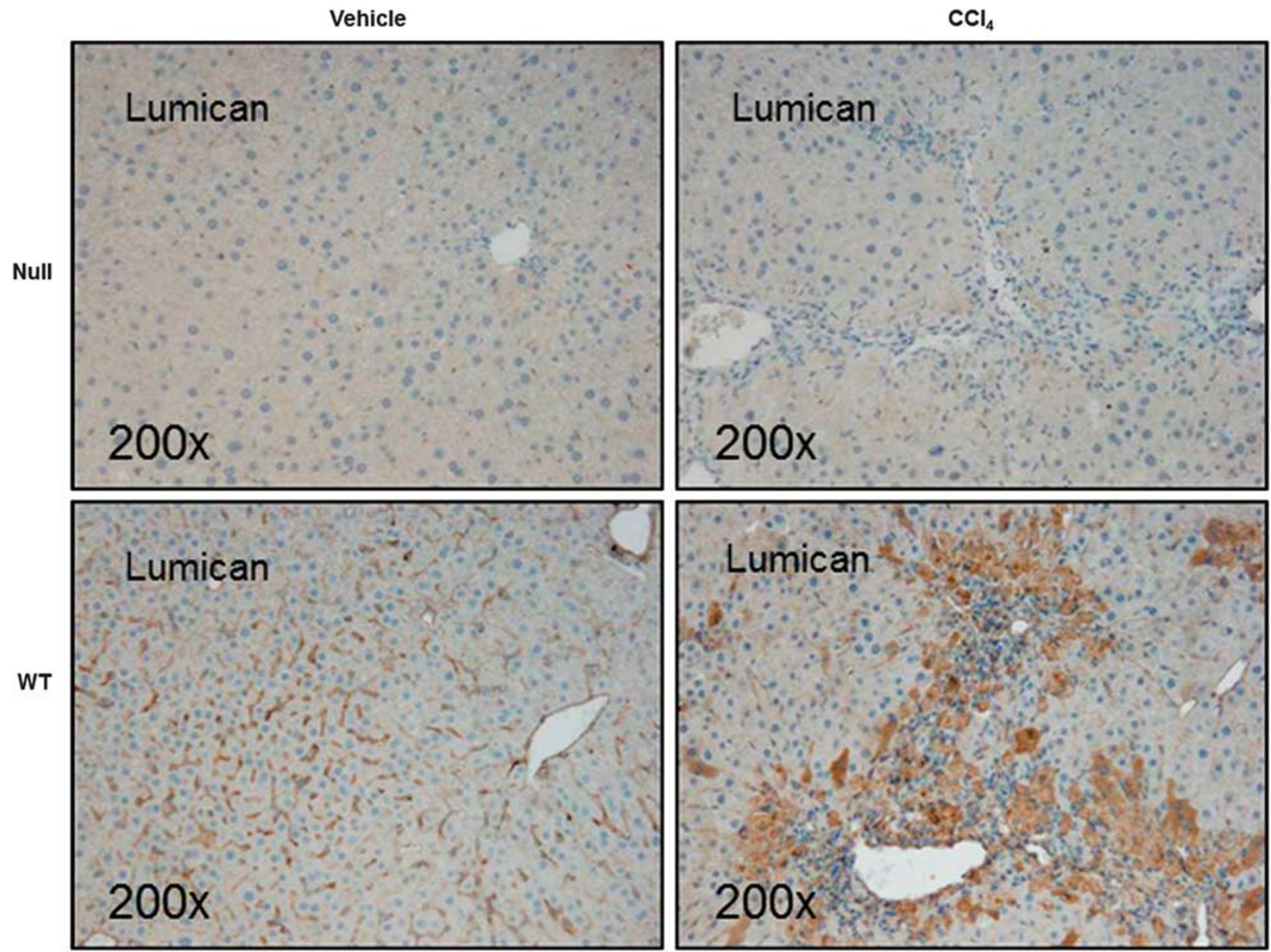

Figure 3 Lumican is over-expressed with $\mathrm{CCl} 4$ administration. Lumican null or WT animals were administered $\mathrm{CCl} 4(n=6)$ or vehicle $(n=4)$ twice weekly for 1 month @ $1 \mathrm{ml} / \mathrm{kg}$. Lumican immunostaining is minimal in null animals. By contrast, in WT animals, lumican staining closely approximates the bridging lesions seen typically in hepato-toxin induced chronic liver injury. Hepatocytes clustered around areas of tissue injury (bridging vein to vein) and inflammation stain intensely for lumican in addition to the hepatic sinusoids. Magnification: $\times 200$.

indicated that mRNA expression was eightfold $(P<0.05)$ and threefold $(P<0.05)$ increased in animals on FF diet and in CCl4-treated animals, respectively. Lumican over-expression in CCl4-treated mice was additionally confirmed by immunoblotting (Figure 2a), where lumican band stretches from 37 to $50 \mathrm{kDa}$ probably reflecting its glycosylated state. We also examined lumican gene expression in clinical samples of HCV infection. Lumican gene expression was fivefold increased in HCV patients $(P<0.001)$. Interestingly, lumican gene expression correlated positively with gene expression of TGF $\beta 1$ in both the diet-induced rodent model of steatohepatitis $\left(r^{2}=0.73\right)$ as well as the CCl4 liver injury model $\left(r^{2}=0.57\right)$, suggesting an association with pro-fibrotic signaling pathways (Figures $2 \mathrm{~b}$ and $\mathrm{c}$ ).

\section{Lumican Expression is Upregulated In Vitro by Pro-Fibrotic and Lipotoxic Signaling}

Since an increased expression of TGF $\beta 1$ is a common response to acute and chronic liver injury, ${ }^{22,23}$ we examined the in vitro effect of TGF $\beta 1$ on lumican expression in primary human hepatocytes over a period of $72 \mathrm{~h}$. Lumican gene expression was significantly upregulated at all time points (Table 2). Similarly, lumican was over-expressed in HuH7 cells exposed to TGF $\beta 1$ (Supplementary Figure 2). Additionally in $\mathrm{HuH7}$ cells, exposure to palmitic acid was associated with a threefold increase in lumican expression $(P=0.05)$ as compared with a twofold increase when exposed to stearic acid.

\section{Lumican Null Mice Are Not Protected Against Hepatic Injury or Inflammation}

Lumican has an established role in collagen fibrillogenesis in nonhepatic tissue. ${ }^{6}$ Taken together with our observations on increased lumican expression in vivo in response to injury and in vitro in response to TGF $\beta 1$ signaling, it appeared likely that lumican may play a role in hepatic fibrosis. To better understand the functional role of lumican, we used the 
Table 3 Comparison of liver enzymes, protein and mRNA expression in lumican WT and null animals administered CCl4

\begin{tabular}{|c|c|c|c|c|c|c|c|c|}
\hline & \multicolumn{2}{|c|}{ Vehicle } & \multicolumn{2}{|c|}{$\mathrm{CCl} 4$} & \multicolumn{4}{|c|}{$P$-values } \\
\hline & WT 1 & Null 2 & WT 3 & Null 4 & 1 vs 2 & 3 vs 4 & 1 vs 3 & 2 vs 4 \\
\hline Serum AST & $288(279)$ & $235(62)$ & $994(362)$ & $1528(1483)$ & 1.000 & 0.936 & 0.130 & 0.07 \\
\hline Lumican & $9.96(4.3)$ & $3.00(0.1)$ & $20.43(1.8)$ & $2.01(2.1)$ & $0.030^{\mathrm{a}}$ & $0.005^{\mathrm{a}}$ & $0.025^{\mathrm{a}}$ & 0.109 \\
\hline Collagen 1 month & $0.18(0.1)$ & $0.13(0.1)$ & $1.34(0.3)$ & $0.49(0.2)$ & 0.662 & $0.028^{\mathrm{a}}$ & $0.028^{\mathrm{a}}$ & 0.081 \\
\hline Collagen 3 months & $0.46(0.3)$ & $0.40(0.2)$ & $4.18(0.9)$ & $2.38(0.7)$ & 1.000 & $0.023^{\mathrm{a}}$ & $0.014^{\mathrm{a}}$ & $0.020^{\mathrm{a}}$ \\
\hline$\alpha-S M A$ & $0.8(0.3)$ & $1.80(0.4)$ & $9.65(1.0)$ & $12.90(2.5)$ & 0.061 & $0.041^{\mathrm{a}}$ & $0.014^{\mathrm{a}}$ & $0.014^{\mathrm{a}}$ \\
\hline $\operatorname{Tgf} \beta 1$ & $1.31(0.4)$ & $1.63(0.9)$ & $3.82(1.1)$ & $4.97(1.8)$ & 0.885 & 0.229 & $0.014^{\mathrm{a}}$ & $0.025^{\mathrm{a}}$ \\
\hline Timp1 & $0.01(0.0)$ & $0.06(0.0)$ & $0.41(0.3)$ & $0.66(0.4)$ & 0.061 & 0.229 & $0.014^{\mathrm{a}}$ & $0.014^{\mathrm{a}}$ \\
\hline Mmp9 & $0.08(0.0)$ & $0.13(0.1)$ & $0.41(0.2)$ & $0.31(0.1)$ & 0.859 & 0.471 & $0.028^{\mathrm{a}}$ & $0.04^{\mathrm{a}}$ \\
\hline Mmp13 & $0.01(0.0)$ & $0.08(0.1)$ & $0.03(0.2)$ & $0.77(0.5)$ & $0.030^{\mathrm{a}}$ & $0.023^{\mathrm{a}}$ & $0.014^{\mathrm{a}}$ & $0.025^{\mathrm{a}}$ \\
\hline
\end{tabular}

Data are presented as mean (s.d.).

Lum, lumican; Coll1a1, collagen $1 \alpha 1$; Tgf $\beta 1$, transforming growth factor $\beta 1$; Timp1, tissue inhibitor of metalloprotease 1 ; Mmp, matrix metalloprotease.

asignificant.

well-established rodent model of CCl4-induced liver injury to determine whether lumican deficiency protected against hepatic fibrosis. We first confirmed that injury was mediated equally in WT and null animals. We determined that gene expression of CYP2E1, the cytochrome that mediates biotransformation of $\mathrm{CCl} 4$ to hepato-toxic $\mathrm{CCl}_{3}$ was similarly regulated in both genotypes (Supplementary Figure 3). As expected, immunohistochemical and gene expression analysis indicated that lumican was minimal in null mice (Figure 3). Distribution and localization of lumican in WT animals was similar to that observed earlier in the acute liver injury model. Of note, lumican staining in WT animals approximated the bridging fibrosis typically associated with chronic hepato-toxin mediated liver injury reinforcing the notion that increased lumican expression is a consequence of injury. Lumican gene expression was fourfold and protein expression was twofold significantly up-regulated $(P<0.05)$ in WT animals administered CCl4 as compared with their vehicle controls. Serum AST, an indicator of hepatic injury, was numerically higher in null animals but was not statistically different from the WT littermates (Table 3). Histological evaluation of H\&E-stained tissue sections revealed characteristic patterns of injury associated with hepato-toxicity in both null and WT animals. Chronic CCl4 administration induced peri-central inflammation with focal necrosis and hepatocellular vacuolization accompanied by aggregates of lymphocytes in both genotypes that appeared more severe in the null animals (Figure 4).

\section{Lumican Null Mice Are Protected Against Hepatic Fibrosis}

Lumican null mice administered CCl4 over a period of 4 weeks exhibited less scarring and deposition of collagen as compared with the WT mice (Figure 5) and additionally in another group maintained for 12 weeks (Supplementary Figure 4). Digital image analysis of picrosirius red stained sections confirmed that percentage area of sirius red staining was significantly higher in WT mice than that of null animals $(P<0.05$; Table 3$)$. Relative gene expression analysis however indicated that collagen gene expression was similarly upregulated in both null and WT animals but significantly increased over their respective controls (Table 3). Hydroxyproline, on the other hand, was numerically lower in null animals $(3.11 \pm 1.27 \mu \mathrm{g} / 100 \mathrm{mg})$ treated with CCl4 than in WT animals $(3.40 \pm 2.39 \mu \mathrm{g} /$ $100 \mathrm{mg}$ ). There was however no statistically significant difference either in collagen gene expression or in hydroxyproline content between the two genotypes administered CCl4. Staining for ASMA, marker for activated stellate cells and myofibroblasts, the primary sources of collagen (Figure 6) in the liver indicated significantly higher 

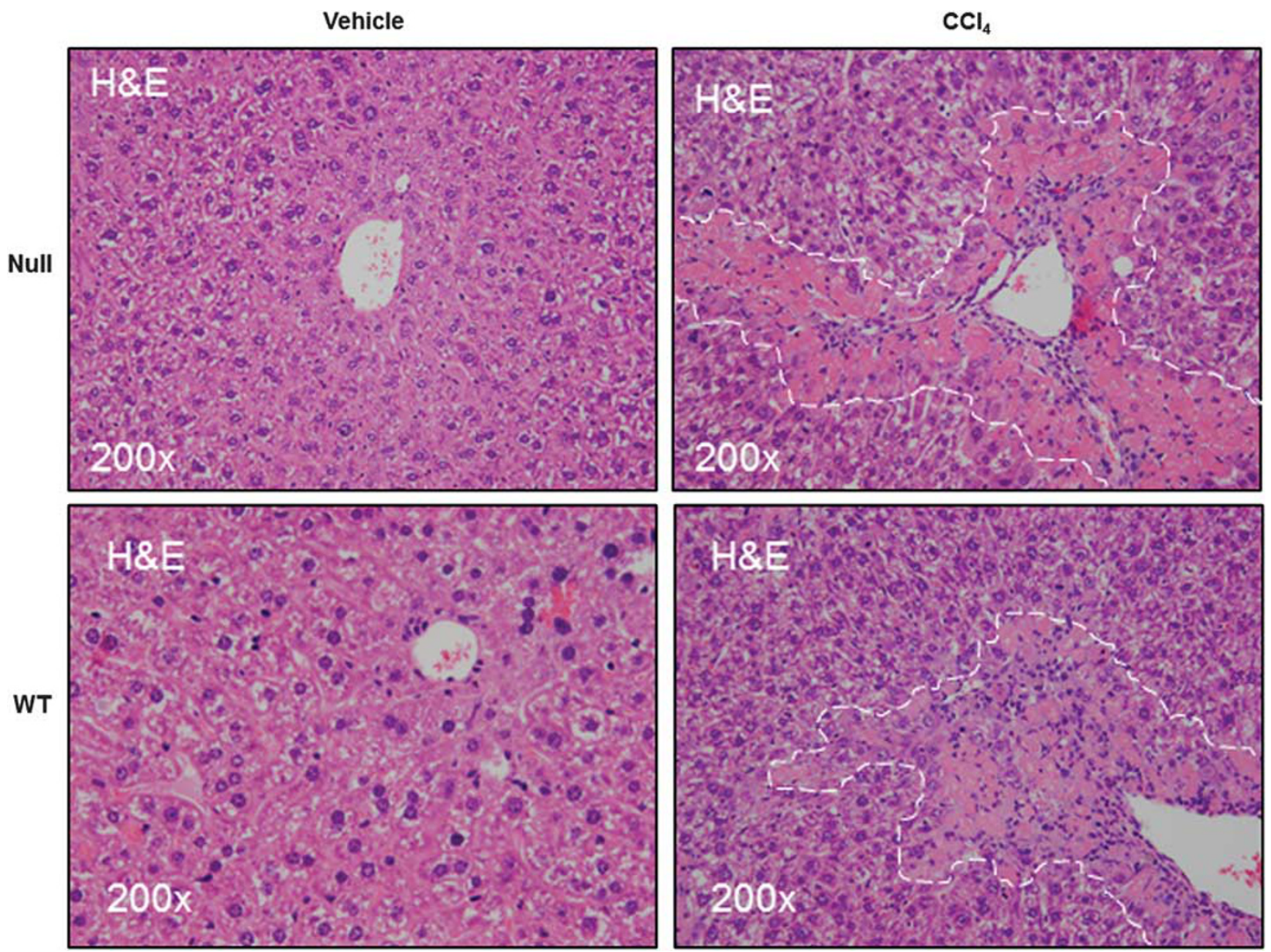

Figure 4 Lumican null mice are not protected against hepatic injury. Lumican null or WT animals were administered $\mathrm{CCl} 4(n=6)$ or vehicle $(n=4)$ twice weekly for 1 month @ $1 \mathrm{ml} / \mathrm{kg}$. H\&E-stained sections of liver show necro-inflammation and hepatocellular vacuolization that appear more severe in Null animals. No injury is seen in liver sections of mice administered vehicle alone.

$(P<0.05)$ expression in null animals (Table 3$)$. With CCl4 treatment, TGF $\beta 1$, the cytokine known to drive fibrosis was similar between genotypes (Table 3 ).

\section{Lumican Null Mice Are Characterized by Increased MMP13 and Increased Proliferation}

The above observations suggested that the protective effect of lumican deficiency occurred downstream of stellate cell/ myofibroblast activation and collagen production. We therefore sought evidence of increased matrix turnover mediated by metalloproteases, MMP2, MMP9, and MMP13 that breakdown fibrillar collagen type 1. Of these, MMP13 was significantly $(P<0.05)$ increased in lumican null animals. Of particular interest, MMP13 was the only gene significantly elevated (eightfold) in null animals treated with vehicle (Table 3). Further, cell proliferation as measured by percentage of Ki67-positive cells was twofold increased $(P<0.001)$ in null animals $(25.8 \pm 7.7)$ as compared with their WT littermates (12.2 \pm 2.5 ; Figure 7$)$.

\section{Hepatic Collagen Fibril Structural Assembly is Impaired in Lumican Null Animals}

Ultra-structural imaging indicated a marked difference in the structural organization of collagen fibrils in lumican null and WT animals. In null animals, collagen fibrils appear scattered, widely dispersed and of differing diameters (Figure 8a). By contrast, in WT animals, collagen fibrils are evenly spaced and of uniform diameter.

\section{Collagen Fibril Formation is Enhanced by the Addition of Recombinant Lumican}

Collagen fibril formation was examined by measuring change in turbidity over time. When recombinant lumican protein was added to the medium, collagen fibril formation was enhanced and occurred sooner (Figure 8b). Absorbance values for 10 and $20 \mu \mathrm{g}$ of recombinant lumican measured over the 60 -min assay time was minimal $(0.006 \pm 0.0001$ and $0.007 \pm 0.0008$ for 10 and $20 \mu \mathrm{g}$, respectively). 


\section{Vehicle}
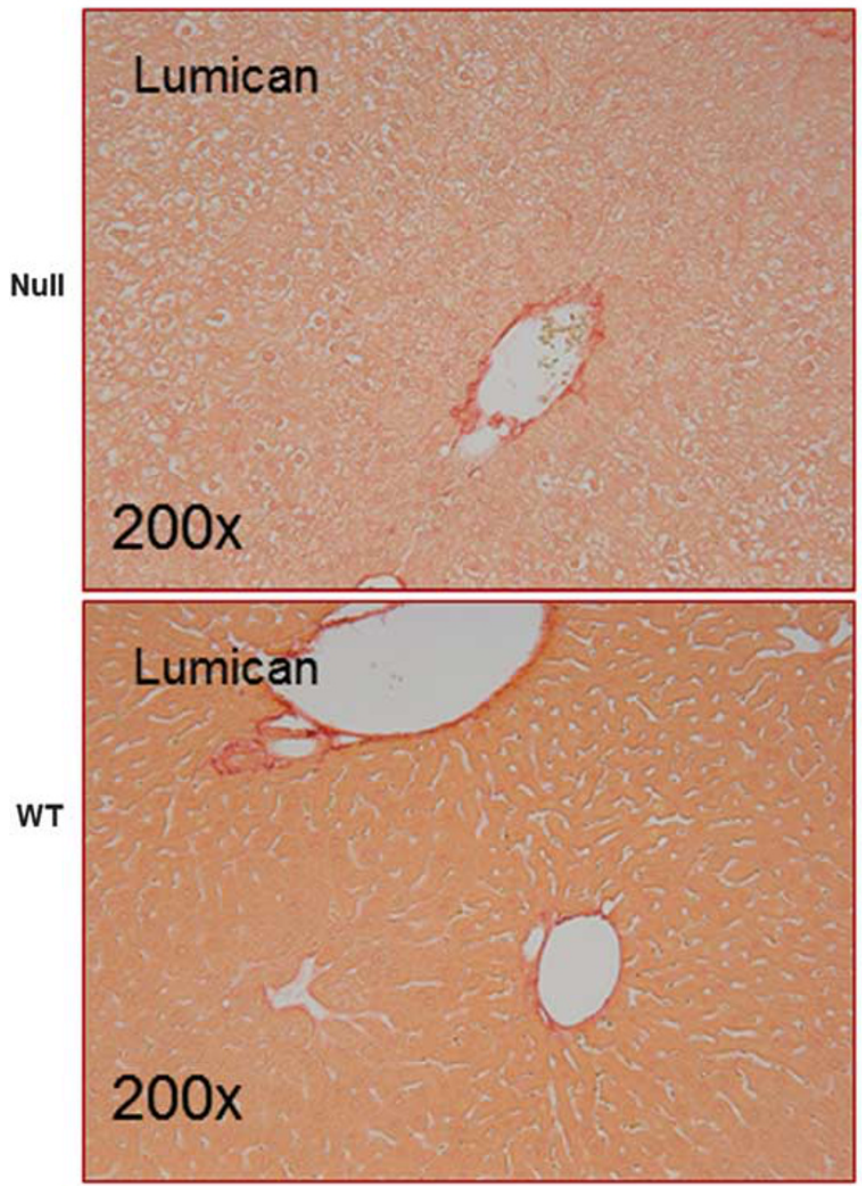
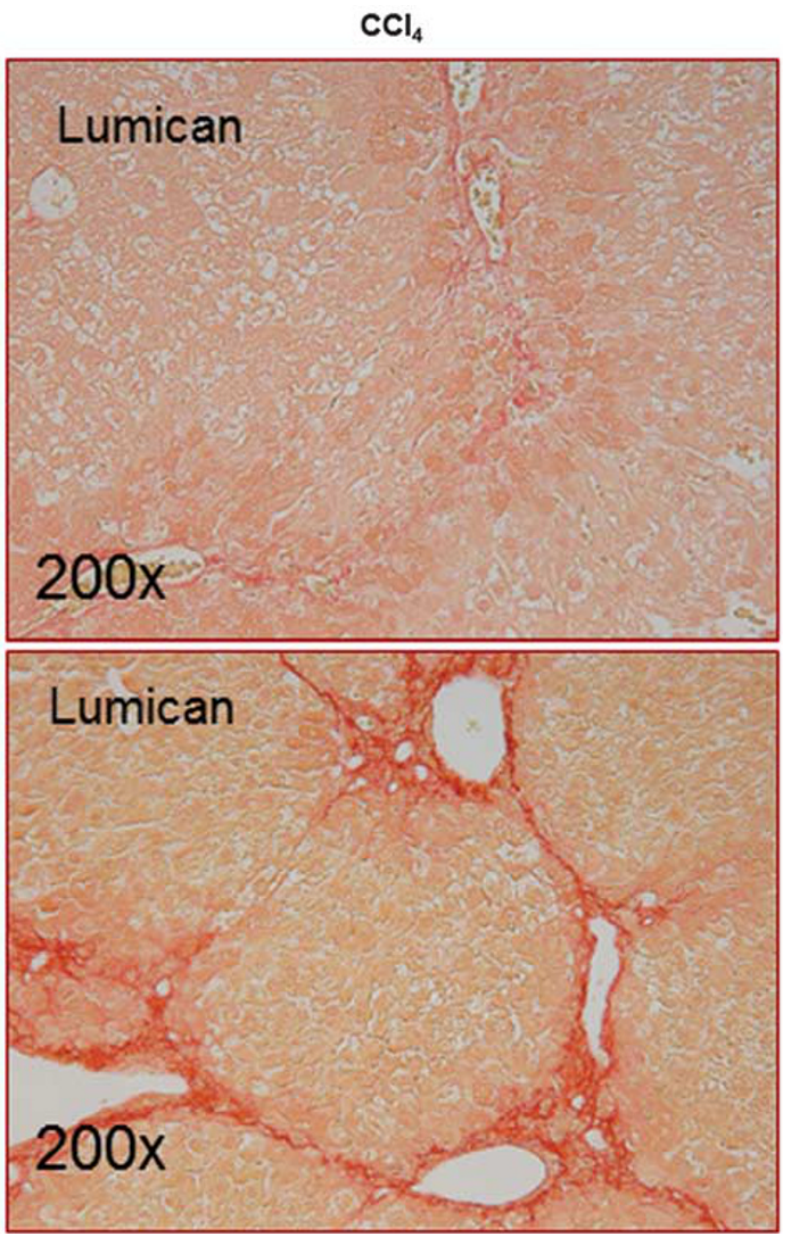

Figure 5 Lumican null animals show decreased hepatic fibrosis. Liver sections of Null and WT animals administered $\mathrm{CCl}_{4}$ or vehicle twice weekly for 1 month at $1 \mathrm{ml} / \mathrm{kg}$ were stained with picrosirius red. There was a twofold decrease in stained area in null animals as compared with the WT animals administered $\mathrm{CCl}_{4}$. Injured and vacuolated hepatocytes are visible in null animals. Magnification: $\times 200$.

\section{DISCUSSION}

In this study, we report on the in vivo modulation of lumican, an ECM proteoglycan, in the context of hepatic injury. Lumican is up-regulated in vivo in experimentally induced steatohepatitis and fibrosis and in clinical HCV. Taken together with our recent observation that lumican expression is progressively over-expressed with increasing severity of $\mathrm{NASH},{ }^{3}$ this suggests that lumican up-regulation may be a common response to hepatic injury. Lumican expression was also increased in vitro in response to pro-fibrotic TGF $\beta 1$ signaling. Further, in a rodent model of CCl4-induced hepatic fibrosis, lumican-deficient mice were protected against fibrosis despite ongoing injury, stellate cell/ myofibroblast activation, and collagen mRNA production. MMP13, a metalloprotease that degrades collagen was significantly up-regulated in null animals. Ultra-structural imaging indicated that collagen fibril assembly was impaired in null animals. These results collectively suggest that the protective effect of lumican deficiency was mediated through impaired collagen fibrillogenesis in conjunction with a rapid matrix turnover.
Lumican, along with other members of the SLRP family such as fibromodulin and decorin, has a well-documented role in collagen assembly. ${ }^{24}$ Being closely associated with collagen, lumican has been detected in almost all tissue types. ${ }^{11,25-29}$ Lumican null mice are characterized by defects in the connective tissue. ${ }^{30}$ Lumican has also been implicated in diverse pathologies, ${ }^{4,30,31}$ often with opposing outcomes associated with both increased and decreased lumican expression. ${ }^{31-36}$ However, it is not known whether these differing outcomes are tissue or disease specific. Further, diverse functional roles have been demonstrated for lumican. ${ }^{14,16,37}$ Very little however, is known about its role in the liver. In an experimental rodent model of thioacetamide-induced hepatic fibrosis, lumican expression remained unchanged. ${ }^{38}$ Nevertheless, in the context of its association with collagen, the excessive accumulation of which is the hallmark of fibrosis, it appeared most likely that lumican may be regulated by pro-fibrotic signaling. In fact, the sum of our in vivo observations in genetically unaltered animal models and our in vitro observations indicated that lumican expression correlated positively with the pro-fibrotic cytokine 

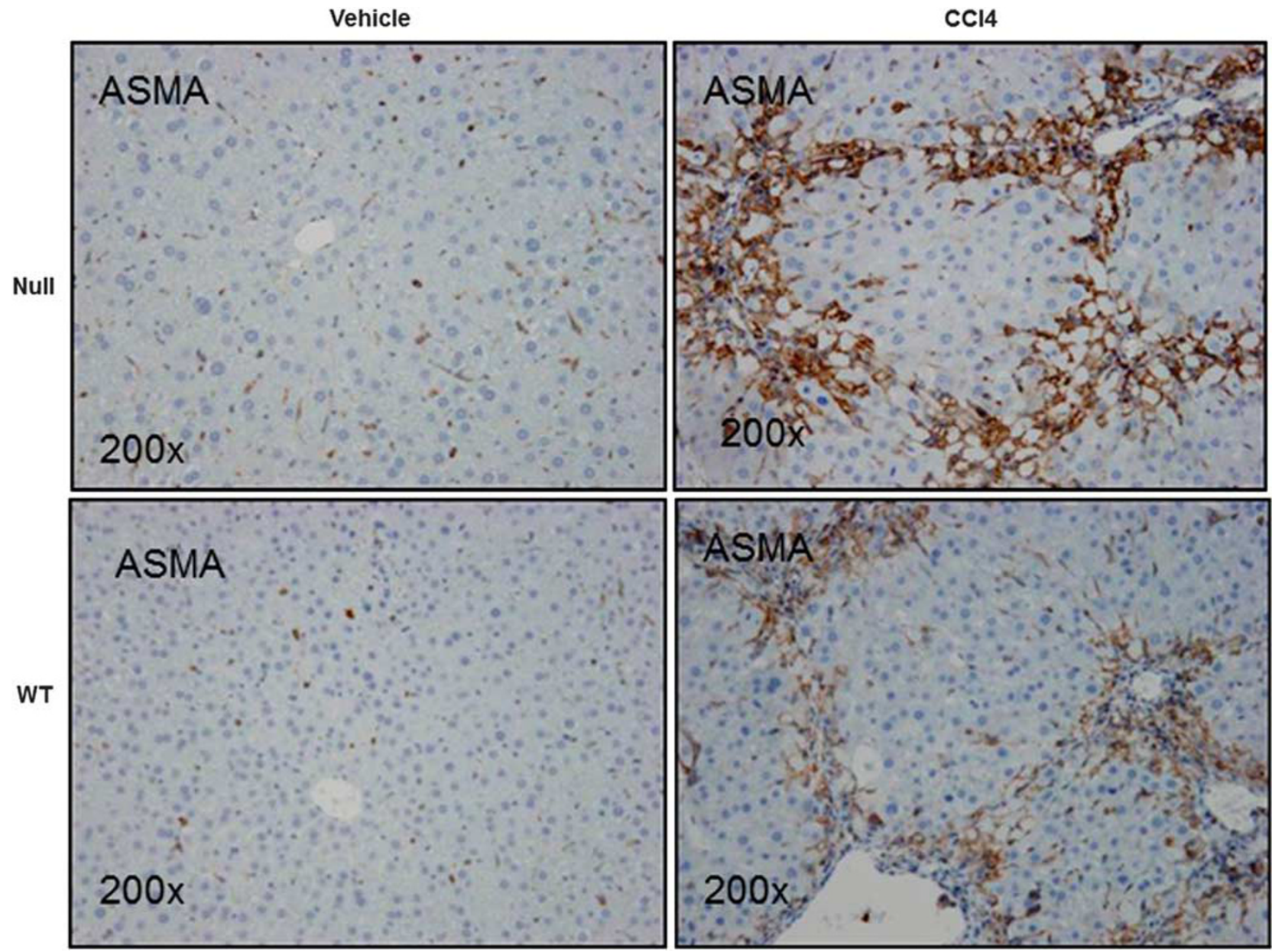

Figure 6 Null animals are characterized by increased ASMA staining. Liver sections of Null and WT animals administered $\mathrm{CCl}_{4}$ or vehicle twice weekly for 1 month at $1 \mathrm{ml} / \mathrm{kg}$ were stained for ASMA, a marker for myofibroblast and stellate cell activation, the major contributors to collagen production. ASMA was increased (1.3-fold) in null animals as compared with their WT littermates administered CCl4. Magnification: $\times 200$.

TGF $\beta 1$. To better understand the functional role of lumican in the fibrotic response, we used the CCl4-induced model of hepatic fibrosis to investigate whether lumican deficiency could abrogate injury and fibrosis. We sought evidence of fibrosis in null and WT animals in the context of hepatic injury, inflammation, matrix remodeling, and proliferation.

Histological evaluation and liver enzyme profile indicated that lumican null animals were not protected against liver injury. However, there was less fibrosis in null animals as evidenced in picrosirius-stained sections (Figure 5; Supplementary Figure 4) despite increased myofibroblast activation or similar levels of TGF $\beta 1$ and collagen mRNA expression. Taken together, these results suggested that the protective effect of lumican deficiency occurred downstream of myofibroblast activation, inflammation, and collagen mRNA production. It is now well accepted that accelerated collagen synthesis is a critical response to cellular injury that is eventually terminated and resolved during the final phase of the wound healing response following restoration of tissue homeostasis. Fibrosis is considered to be the consequence of a failure to terminate this wound healing response. ${ }^{22} \mathrm{~A}$ net increase in collagen-rich 'scar' tissue occurs when accumulation exceeds breakdown. ${ }^{39}$ Fibrosis may thus reflect either an increase in collagen synthesis or a decrease in collagen degradation. In the present study, although we observed increased collagen gene expression in both null and WT animals, accumulation of collagen into a well-defined scar tissue occurred only in WT animals (Figure 5; Supplementary Figure 4). We therefore sought evidence for this anomaly by looking at the (a) structural integrity of collagen and (b) mediators of collagen degradation, viz., the metalloproteases.

Ultra-structural imaging of liver in null animals indicated collagen fibrils that were both unevenly distributed and having variable diameters as compared with the uniformly packed and evenly distributed fibrils observed in WT animals. Both features have been previously demonstrated in the cornea, skin, and tail tendon ${ }^{4,6,40}$ of lumican-deficient animals and our observation extends this characteristic feature of lumican null animals to the liver also. Lumican as well as other SLRP's, are known to bind collagen fibrils 


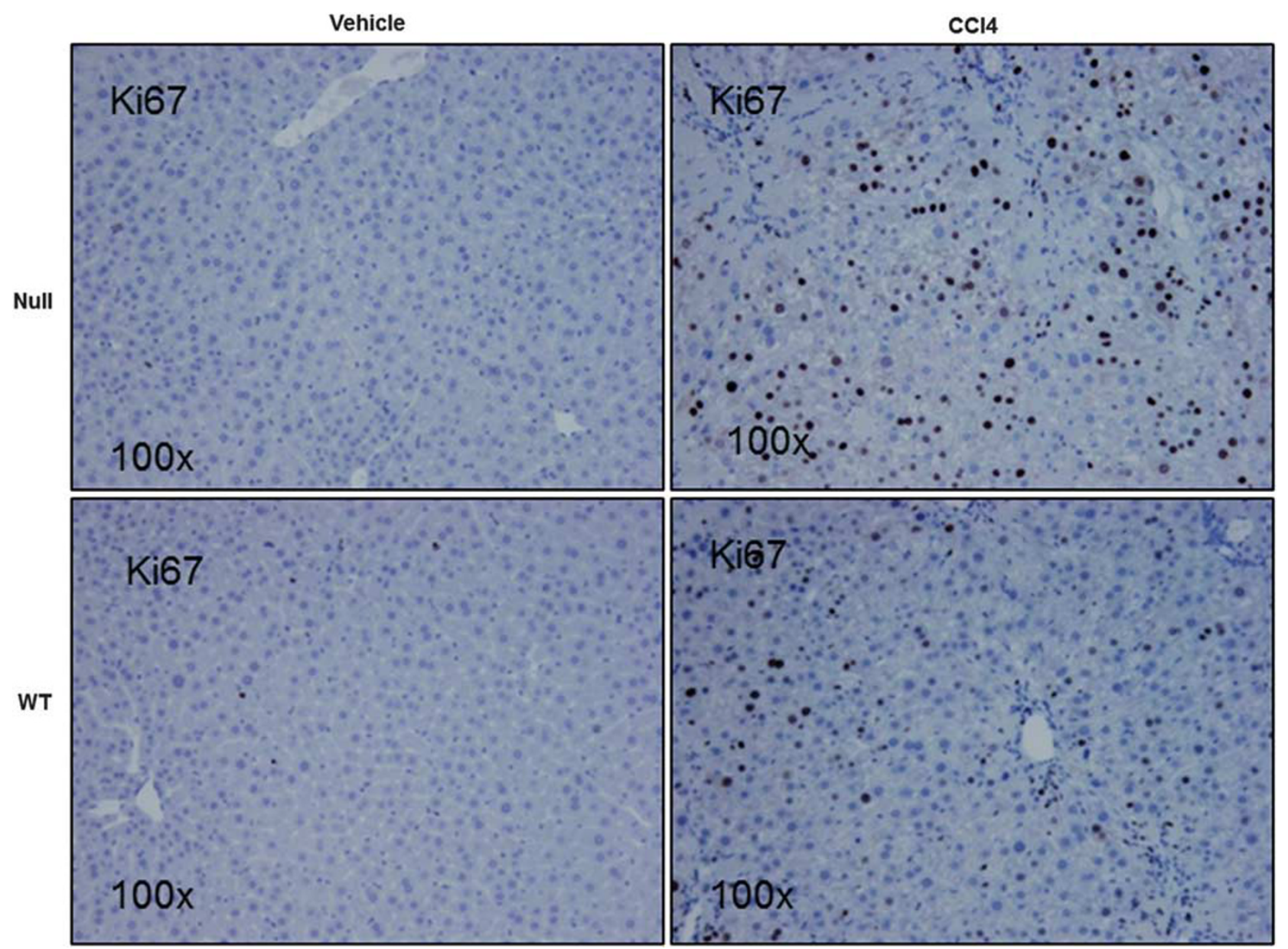

Figure $7 \mathrm{Null}$ animals are characterized by increased cell proliferation. Liver sections of Null and WT animals administered $\mathrm{CCl}_{4}$ or vehicle twice weekly for 1 month at $1 \mathrm{ml} / \mathrm{kg}$ were stained for Ki67, a marker for proliferating cells. Ki67-positive cells were twofold significantly increased in Null animals as compared with their WT counterparts. Magnification: $\times 100$.

together, ${ }^{41,42}$ enhancing their stability and regulating the kinetics of collagen assembly. Structurally, lumican is horseshoe shaped, attaching to collagen fibrils via its concave surface. ${ }^{43}$ In its absence, however, it is possible for other members of the SLRP family, particularly fibromodulin that binds to collagen at the same site as lumican $^{42}$ to compensate for lumican deficiency. We therefore assessed the WT and null animals for presence of fibromodulin. Fibromodulin was similarly expressed in CCl4-treated null and WT genotypes (Supplementary Figure 5), further reinforcing previous observations on the relevance of lumican in maintaining a mature collagen structure. In rodent neonates, lumican was shown essential for the maturation of collagen fibril. ${ }^{44}$ The lack of hepatic fibrosis in null animals may therefore have been mediated, at least in part, by impaired fibril assembly. Indirect evidence of the effect of lumican on collagen fibril formation is also provided here using the fibril formation assay. Recombinant lumican enhanced and hastened the formation of collagen fibrils when added to collagen corroborating earlier observations. ${ }^{21}$
Poorly cross-linked collagen fibrils that are not fully functional are at risk for degradation by proteolytic enzymes. ${ }^{45}$ We therefore sought evidence of matrix turnover mediated particularly by those proteases that degrade collagen, MMP2, MMP9, and MMP13. Among these, the interstitial collagenase MMP13, the rodent equivalent of human MMP1, was significantly increased ( $>20$-fold over the WT animals, Table 3) while MMP9 was similarly regulated in null and WT littermates. Interstitial collagenase MMP1/13 is known to orchestrate proteolytic degradation of fibrillar collagen to telopeptides that breakdown to gelatin derivatives for eventual clearance through urine. ${ }^{46,47}$ The shift in values for collagen-related data in the null animals as compared with their WT littermates: from a higher gene expression to lower hydroxyproline content would suggest that this mechanism is operational. Matrix molecules like lumican and fibromodulin that bind to collagen fibril at sites adjacent to the collagenase cleavage activity can sterically impede and retard this process, ${ }^{4-50}$ with lumican being more resistant to MMP-mediated degradation than 

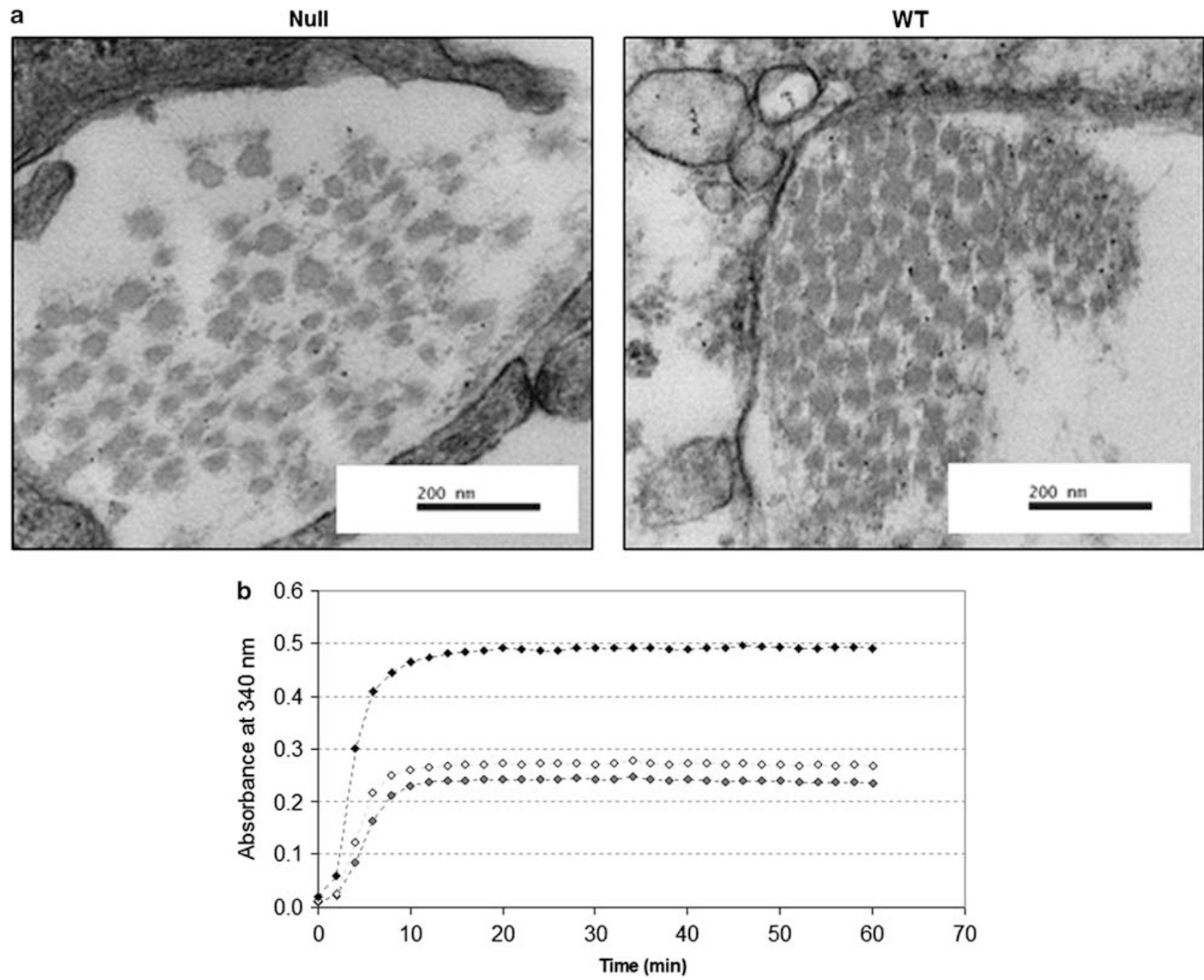

Figure 8 (a) Ultra-structural micrographs of healthy, age-matched Null and WT animals. In null animals, collagen fibrils are irregularly distributed and have unequal diameters. By contrast, in WT animals, collagen fibrils are of even diameter and are packed uniformly. Magnification: $\times 80000$ (b). Collagen fibril formation was assayed spectrophotometrically with the addition of recombinant lumican protein. Collagen fibril was quantitatively enhanced and hastened by the addition of recombinant lumican and was dose dependent.

fibromodulin. ${ }^{46,48}$ Lumican null mice were characterized by poorly assembled collagen fibrils and increased levels of interstitial collagenase. This would suggest that while lumican contributed to collagen fibril stability making them more resistant to proteolytic degradation in WT animals; its absence in null animals enabled the reverse: exposing poorly assembled collagen fibrils to degradation by MMP13. Increased expression of MMP13 appears to be an inherent character of lumican null animals as this was the only gene whose expression was significantly different between null and WT animals administered vehicle alone: a response likely arising from the need to continuously remove poorly assembled collagen fibrils even in the absence of significant injury.

Timely replacement of dead and injured cells can accelerate the recovery phase after injury. In null animals, Ki67, a marker for cell proliferation was significantly increased (twofold) over that of WT animals, indicating that replacement of injured cells occurred more rapidly in null animals. These observations corroborate earlier studies where inhibiting gene expression of lumican enhanced cell proliferation. ${ }^{10,51}$ Cell proliferation was mediated by reduced expression of the cyclin kinase inhibitor, $\mathrm{p} 21 / \mathrm{Wakf}^{10}$ that was also observed in the current study (data not shown), suggesting induction of a similar pathway. The enhanced proliferation would have also contributed to faster recovery observed in lumican null animals over the long term.

Several features of the study warrant further investigation. In experimental models, lumican has been shown to be a versatile protein, interacting and binding with other proteins such as TGF $\beta 2,{ }^{52}$ FasL, ${ }^{15}$ TLR4, ${ }^{14}$ and integrins ${ }^{37}$ thereby affecting downstream signaling. A delayed wound healing response has been demonstrated in lumican null animals following injury of the cornea ${ }^{53,54}$ accompanied with delayed 
recruitment of macrophages. As fibrosis is a response to cellular injury, most of these responses to experimentally induced acute injury, may involve pathways that have relevance to those leading to fibrosis. The increased expression of TGF $\beta 1$ observed in null animals of the current study may thus have resulted from impaired binding of the secreted cytokine. Likewise, it appears that the kinetics of the wound healing response in the hepatic environment is differentially regulated in the null and WT animals. During normal wound healing, inflammatory cytokines, growth factors, acute phase proteins, matrix proteases, and several others peak and return to basal levels in distinct but overlapping phases to restore tissue integrity. ${ }^{55}$ Animal models of induced fibrosis rely on repetitive doses of toxin to maintain a pro-inflammatory state. It is reasonable however, to presume that key genes involved in healing maintain their phased response in the intervals between toxin administrations. In the present study, all null and WT animals were given CCl4 twice weekly and sacrificed on the second day 36-40 h after the last injection. At this time point, the histology in WT animals as well as decreased expression of primary response genes such as TGF $\beta 1$, ASMA, and collagen suggests an earlier restoration to basal levels. On the other hand, their increased expression in null animals would suggest either a persistent or a delayed activation of healing response. Nevertheless, it is worth noting that in null animals, the signals for increased proliferation and increased matrix turnover have already been triggered or enhanced contributing to an earlier clearance of collagen from the matrix and an earlier restoration of tissue integrity.

In summary, we present data that during the fibrotic process, the proteoglycan lumican contributes importantly to liver fibrosis by maintaining collagen fibril stability. We demonstrate that in the absence of lumican, hepatic accumulation of collagen can be attenuated. Lumican deficiency could also promote rapid proliferation and restoration of injured tissue. Lumican may therefore represent an attractive therapeutic target for the treatment of hepatic fibrosis.

Supplementary Information accompanies the paper on the Laboratory Investigation website (http://www.laboratoryinvestigation.org)

\section{ACKNOWLEDGEMENTS}

We acknowledge the able assistance of Debbie Hintz in the preparation and submission of this manuscript. This work has been supported by Public Health Service Grant NIDDK RO1 DK069757-01 and GCRC RR00585.

\section{DISCLOSURE/CONFLICT OF INTEREST}

The authors declare no conflict of interest.

1. Kmiec Z. Cooperation of liver cells in health and disease. Adv Anat Embryol Cell Biol 2001;161:III-XIII, 1-151.

2. Reeves HL, Friedman SL. Activation of hepatic stellate cells-a key issue in liver fibrosis. Front Biosci 2002;7:d808-d826.

3. Charlton M, Viker K, Krishnan A, et al. Differential expression of lumican and fatty acid binding protein-1: new insights into the histologic spectrum of nonalcoholic fatty liver disease. Hepatology 2009;49:1375-1384.

4. Kao WW, Funderburgh JL, Xia Y, et al. Focus on molecules: lumican. Exp Eye Res 2006;82:3-4.

5. Chakravarti $\mathrm{S}$, Stallings $\mathrm{RL}$, SundarRaj $\mathrm{N}$, et al. Primary structure of human lumican (keratan sulfate proteoglycan) and localization of the gene (LUM) to chromosome 12q21.3-q22. Genomics 1995;27: 481-488.

6. Chakravarti S, Magnuson T, Lass $\mathrm{JH}$, et al. Lumican regulates collagen fibril assembly: skin fragility and corneal opacity in the absence of lumican. J Cell Biol 1998;141:1277-1286.

7. Chakravarti S, Petroll WM, Hassell JR, et al. Corneal opacity in lumicannull mice: defects in collagen fibril structure and packing in the posterior stroma. Invest Ophthalmol Vis Sci 2000;41:3365-3373.

8. Ameye L, Young MF. Mice deficient in small leucine-rich proteoglycans: novel in vivo models for osteoporosis, osteoarthritis, Ehlers-Danlos syndrome, muscular dystrophy, and corneal diseases. Glycobiology 2002;12:107R-116RR.

9. Albig AR, Roy TG, Becenti DJ, et al. Transcriptome analysis of endothelial cell gene expression induced by growth on matrigel matrices: identification and characterization of MAGP-2 and lumican as novel regulators of angiogenesis. Angiogenesis 2007;10:197-216.

10. Li Y, Aoki T, Mori Y, et al. Cleavage of lumican by membrane-type matrix metalloproteinase-1 abrogates this proteoglycan-mediated suppression of tumor cell colony formation in soft agar. Cancer Res 2004;64:7058-7064.

11. Brezillon $S$, Venteo $L$, Ramont $L$, et al. Expression of lumican, a small leucine-rich proteoglycan with antitumour activity, in human malignant melanoma. Clin Exp Dermatol 2007;32:405-416.

12. Ishiwata T, Yamamoto T, Kawahara K, et al. Enhanced expression of lumican inhibited the attachment and growth of human embryonic kidney 293 cells. Exp Mol Pathol, 88:363-370.

13. Seomun $Y$, Joo CK. Lumican induces human corneal epithelial cell migration and integrin expression via ERK 1/2 signaling. Biochem Biophys Res Commun 2008;372:221-225.

14. Wu F, Vij N, Roberts $\mathrm{L}$, et al. A novel role of the lumican core protein in bacterial lipopolysaccharide-induced innate immune response. J Biol Chem 2007;282:26409-26417.

15. Vij N, Roberts L, Joyce S, et al. Lumican regulates corneal inflammatory responses by modulating Fas-Fas ligand signaling. Invest Ophthalmol Vis Sci 2005;46:88-95.

16. Vij N, Roberts L, Joyce $\mathrm{S}$, et al. Lumican suppresses cell proliferation and aids Fas-Fas ligand mediated apoptosis: implications in the cornea. Exp Eye Res 2004;78:957-971.

17. Nikitovic D, Katonis $P$, Tsatsakis $A$, et al. Lumican a small leucine-rich proteoglycan. IUBMB Life 2008;60:818-823.

18. Charlton M, Krishnan A, Viker K, et al. The fast food diet mouse - a novel small animal model of NASH with high histologic and physiologic fidelity to the human condition. Am J Physiol Gastrointest Liver Physiol 2011;301:G825-3411.

19. Krishnan A, Viker K, Rietema $\mathrm{H}$, et al. Prolonged engraftment of human hepatocytes in mice transgenic for the deleted form of human hepatocyte growth factor. Hepatol Res 2007;37:854-862.

20. Cazanave SC, Mott JL, Elmi NA, et al. JNK1-dependent PUMA expression contributes to hepatocyte lipoapoptosis. J Biol Chem 2009;284:26591-26602.

21. Neame PJ, Kay CJ, McQuillan DJ, et al. Independent modulation of collagen fibrillogenesis by decorin and lumican. Cell Mol Life Sci 2000; 57:859-863.

22. Leask A, Abraham DJ. TGF-beta signaling and the fibrotic response. FASEB J 2004;18:816-827.

23. Matsuzaki K, Murata M, Yoshida K, et al. Chronic inflammation associated with hepatitis $C$ virus infection perturbs hepatic transforming growth factor beta signaling, promoting cirrhosis and hepatocellular carcinoma. Hepatology 2007;46:48-57.

24. Rada JA, Cornuet PK, Hassell JR. Regulation of corneal collagen fibrillogenesis in vitro by corneal proteoglycan (lumican and decorin) core proteins. Exp Eye Res 1993;56:635-648.

25. Dolhnikoff M, Morin J, Roughley PJ, et al. Expression of lumican in human lungs. Am J Respir Cell Mol Biol 1998;19:582-587.

26. Schaefer L, Grone HJ, Raslik I, et al. Small proteoglycans of normal adult human kidney: distinct expression patterns of decorin, biglycan, fibromodulin, and lumican. Kidney Int 2000;58:1557-1568. 
27. Matheson S, Larjava H, Hakkinen L. Distinctive localization and function for lumican, fibromodulin and decorin to regulate collagen fibril organization in periodontal tissues. J Periodontal Res 2005;40:312-324.

28. Melrose J, Fuller ES, Roughley PJ, et al. Fragmentation of decorin, biglycan, lumican and keratocan is elevated in degenerate human meniscus, knee and hip articular cartilages compared with agematched macroscopically normal and control tissues. Arthritis Res Ther 2008;10:R79.

29. Raouf A, Ganss B, McMahon C, et al. Lumican is a major proteoglycan component of the bone matrix. Matrix Biol 2002;21:361-367.

30. Chakravarti S. Functions of lumican and fibromodulin: lessons from knockout mice. Glycoconj J 2002;19:287-293.

31. Nikitovic D, Berdiaki A, Zafiropoulos A, et al. Lumican expression is positively correlated with the differentiation and negatively with the growth of human osteosarcoma cells. FEBS J 2008;275:350-361.

32. Matsuda $Y$, Yamamoto $T$, Kudo $M$, et al. Expression and roles of lumican in lung adenocarcinoma and squamous cell carcinoma. Int J Oncol 2008;33:1177-1185.

33. Onda $\mathrm{M}$, Ishiwata $\mathrm{T}$, Kawahara $\mathrm{K}$, et al. Expression of lumican in thickened intima and smooth muscle cells in human coronary atherosclerosis. Exp Mol Pathol 2002;72:142-149.

34. Seya T, Tanaka N, Shinji S, et al. Lumican expression in advanced colorectal cancer with nodal metastasis correlates with poor prognosis. Oncol Rep 2006;16:1225-1230.

35. Troup S, Njue C, Kliewer EV, et al. Reduced expression of the small leucine-rich proteoglycans, lumican, and decorin is associated with poor outcome in node-negative invasive breast cancer. Clin Cancer Res 2003;9:207-214.

36. Brezillon S, Zeltz C, Schneider L, et al. Lumican inhibits B16F1 melanoma cell lung metastasis. J Physiol Pharmacol 2009;60(Suppl 4):15-22.

37. Lee $S$, Bowrin $K$, Hamad AR, et al. Extracellular matrix lumican deposited on the surface of neutrophils promotes migration by binding to beta2 integrin. J Biol Chem 2009;284:23662-23669.

38. Krull NB, Gressner AM. Differential expression of keratan sulphate proteoglycans fibromodulin, lumican and aggrecan in normal and fibrotic rat liver. FEBS Lett 1992;312:47-52.

39. Bataller R, Brenner DA. Liver fibrosis. J Clin Invest 2005;115:209-218.

40. Austin BA, Coulon C, Liu CY, et al. Altered collagen fibril formation in the sclera of lumican-deficient mice. Invest Ophthalmol Vis Sci 2002;43: 1695-1701.

41. lozzo RV. Proteoglycans: structure, function, and role in neoplasia. Lab Invest 1985;53:373-396.
42. Kalamajski $\mathrm{S}$, Oldberg A. Homologous sequence in lumican and fibromodulin leucine-rich repeat 5-7 competes for collagen binding. $J$ Biol Chem 2009:284:534-539.

43. Scott JE. Proteodermatan and proteokeratan sulfate (decorin, lumican/fibromodulin) proteins are horseshoe shaped. Implications for their interactions with collagen. Biochemistry (Mosc) 1996;35: 8795-8799.

44. Song J, Lee YG, Houston J, et al. Neonatal corneal stromal development in the normal and lumican-deficient mouse. Invest Ophthalmol Vis Sci 2003;44:548-557.

45. Chung HJ, Steplewski A, Chung KY, et al. Collagen fibril formation. A new target to limit fibrosis. J Biol Chem 2008;283:25879-25886.

46. Monfort J, Tardif G, Reboul P, et al. Degradation of small leucine-rich repeat proteoglycans by matrix metalloprotease-13: identification of a new biglycan cleavage site. Arthritis Res Ther 2006;8:R26.

47. Diez J, Laviades C. Monitoring fibrillar collagen turnover in hypertensive heart disease. Cardiovasc Res 1997;35:202-205.

48. Geng Y, McQuillan D, Roughley PJ. SLRP interaction can protect collagen fibrils from cleavage by collagenases. Matrix Biol 2006;25: 484-491.

49. Sztrolovics R, White RJ, Poole AR, et al. Resistance of small leucine-rich repeat proteoglycans to proteolytic degradation during interleukin-1stimulated cartilage catabolism. Biochem J 1999;339(Pt 3):571-577.

50. Scott JE, Haigh M. Identification of specific binding sites for keratan sulphate proteoglycans and chondroitin-dermatan sulphate proteoglycans on collagen fibrils in cornea by the use of cupromeronic blue in 'critical-electrolyte-concentration' techniques. Biochem J 1988;253:607-610.

51. Ishiwata T, Fujii T, Ishiwata $\mathrm{S}$, et al. Effect of morpholino antisense oligonucleotide against lumican mRNA in human embryonic kidney (HEK) 293 cells. Pathol Int 2004:54:77-81.

52. Nikitovic D, Chalkiadaki G, Berdiaki A, et al. Lumican regulates osteosarcoma cell adhesion by modulating TGFbeta2 activity. Int J Biochem Cell Biol 2011;43:928-935.

53. Hayashi Y, Call MK, Chikama T, et al. Lumican is required for neutrophi extravasation following corneal injury and wound healing. J Cell Sci 2010;123(Pt 17):2987-2995.

54. Saika S, Shiraishi A, Liu CY, et al. Converse RL, et al. Role of lumican in the corneal epithelium during wound healing. J Biol Chem 2000; 275:2607-2612.

55. Velnar T, Bailey T, Smrkolj V. The wound healing process: an overview of the cellular and molecular mechanisms. J Int Med Res 2009;37: 1528-1542. 